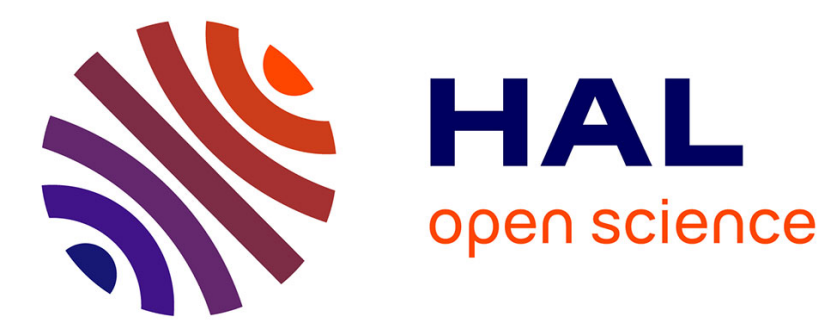

\title{
Minority carrier trap measurements in schottky barriers on N-type LPE GaAs
}

J. Piqueras

\section{To cite this version:}

J. Piqueras. Minority carrier trap measurements in schottky barriers on N-type LPE GaAs. Revue de Physique Appliquée, 1977, 12 (12), pp.1819-1821. 10.1051/rphysap:0197700120120181900 . jpa00244408

\section{HAL Id: jpa-00244408 https://hal.science/jpa-00244408}

Submitted on 1 Jan 1977

HAL is a multi-disciplinary open access archive for the deposit and dissemination of scientific research documents, whether they are published or not. The documents may come from teaching and research institutions in France or abroad, or from public or private research centers.
L'archive ouverte pluridisciplinaire HAL, est destinée au dépôt et à la diffusion de documents scientifiques de niveau recherche, publiés ou non, émanant des établissements d'enseignement et de recherche français ou étrangers, des laboratoires publics ou privés. 
Classification

Physics Abstracts

$73.40 \mathrm{~N}$

\title{
MINORITY CARRIER TRAP MEASUREMENTS IN SCHOTTKY BARRIERS ON N-TYPE LPE GaAs
}

\author{
J. PIQUERAS \\ Laboratorio de Semiconductores, \\ Instituto de Física del Estado Sólido (C. S. I. C. - U. A. M.), \\ Universidad Autónoma de Madrid, Cantoblanco, Madrid, Spain \\ (Reçu le 10 juin 1977, révisé le 26 juillet 1977, accepté le 5 septembre 1977)
}

\begin{abstract}
Résumé. - La technique de mesure transitoire de photocapacitance a été appliquée aux barrières de Schottky semi-transparentes pour détecter les pièges de porteurs minoritaires dans les jonctions $\mathrm{p}^{+}-\mathrm{n}$ au lieu de la méthode classique de mesures transitoires de capacité. De cette manière, et sous certaines conditions, il est possible de détecter et de mesurer le nombre de pièges de porteurs majoritaires et minoritaires dans les barrières de Schottky. La méthode s'applique bien aux barrières de Schottky AsGa sur couches épitaxiques obtenues en phase liquide. Un piège à trou a été mis en évidence à $0,57 \mathrm{eV}$ au-dessus de la bande de valence. Ce résultat est en bon accord avec celui trouvé dans les jonctions $n-p^{+}$sur couche fabriquée en phase liquide.
\end{abstract}

Abstract. - Photocapacitance transient technique has been applied to Schottky semitransparent barriers as an alternative method, instead of the classical capacitance voltage transient method in $\mathrm{p}^{+}$-n junctions for detecting minority carrier traps. In such a way and, under certain conditions, it is possible to detect and measure both majority and minority traps in Schottky barriers. The method applies well to Schottky barriers in LPE GaAs. A hole trap at $0.57 \mathrm{eV}$ above valence band has been found in reasonable agreement with results in $n-p^{+}$junctions in which $n$-layer was grown by LPE.

In the past five years, considerable effort has been put forth in determining deep impurity states in semiconductors. In a recent paper, Sah [1] gives a very complete and interesting review of the different methods. Transient capacitance [2] has been proved to be the more reliable and useful method, although certain refinements have been introduced in order to extend the range in energies to be determined $[3,4]$.

In n-type material, majority carrier deep traps are generally determined in Schottky barriers while it is necessary to perform $\mathrm{p}^{+}-n$ junctions for measuring minority carrier traps [5].

In this paper, an alternative method which permits determination, under certain conditions, of majority and minority carrier traps has been developed. Under strong illumination across semitransparent Schottky barriers the trapping state can be inverted and a hole trap can be observed.

Assume a Schottky barrier on an n-type material with a deep center in the upper half of the gap. Simply by applying a negative voltage, a capacitance transient can be seen and from this, information can be obtained about energy level and concentration of the trap. However, if the deep center yields near or below the gap center, it is probable that applying a negative bias no transient can be observed because the electrons remain attached to the trap, or in other words, the time constant is extremely large. This is because $e_{\mathrm{p}} \gg \boldsymbol{e}_{\mathrm{n}}$, (hole trap) and $e_{\mathrm{n}}$ should be very small or negligible.

Let us go on to consider a semitransparent Schottky barrier on n-type material in which hole emission rate is much higher than the electron emission rate $e_{\mathrm{p}} \gg e_{\mathrm{n}} r$ (see Fig. 1a). Providing carrier injection from illumination across the Schottky barrier, electrons will move towards the ohmic contact while holes travel towards the metallic barrier being trapped by the deep centers which become neutral. Thus, capacitance is increased. On the other hand, the electrons which move towards the ohmic contact are accumulated at the end of the depletion layer causing it to narrow and thus a capacitance increase.

When light is switched off, deep traps emit holes and the level and concentration of the deep center can be obtained from the corresponding transient decay, in the assumption that all traps have been filled.

If the light intensity is strong enough, all traps become empty and the remaining electron-hole pairs created by the light cause an additional increase of the capacitance, that is, the excess electrons accumulate at the end near the ohmic contact, while excess holes remain near the barrier and the depletion layer becomes narrower (see Fig. 1b). 


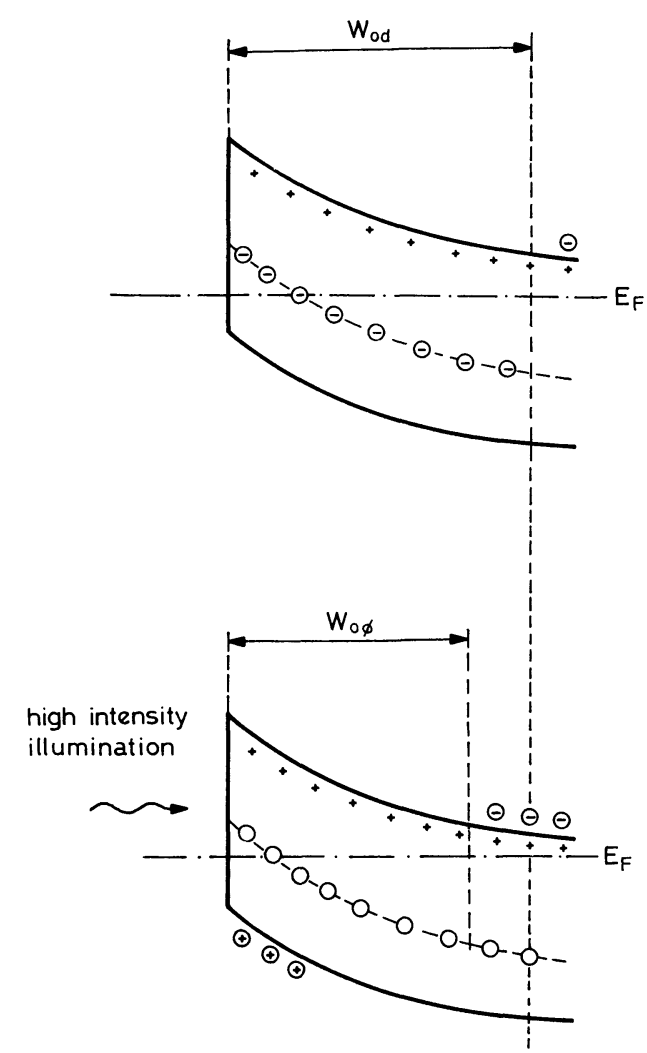

FIG. 1. - (a) Schottky barrier on n-type material with a hole trap in the dark. (b) Schottky barrier on n-type material with a hole trap under strong illumination.

In this case, when light is switched off, the capacitance transient has two components : a quick one due to recombination of excess electron-hole pairs and another slow transient due to hole emission from the deep center.

At any time other depletion layer width can be obtained from a double integration of the corresponding Poisson equation, and results

$$
w=\sqrt{\frac{2 \varepsilon V_{\mathrm{bi}}}{q\left(N_{\mathrm{s}}-N_{\mathrm{t}}^{-}\right)}}
$$

where $V_{\mathrm{bi}}$ is the built-in voltage ; $N_{\mathrm{s}}$ the concentration of shallow donor and

$$
N_{\mathrm{t}}^{-}=N_{\mathrm{t}}\left|1-\exp \left(-e_{\mathrm{p}} t\right)\right|
$$

where $N_{\mathrm{t}}$ is the deep center concentration.

Thus, the hole emission rate can be obtained from the slope of the capacitance transient at time zero, that is

$$
\left.\frac{\mathrm{d} C}{\mathrm{~d} t}\right|_{\mathrm{t}=0}=-\frac{C_{0} N_{\mathrm{t}}}{2 N_{\mathrm{s}}} e_{\mathrm{p}}
$$

where $C_{0}$ is the capacitance when all traps are empty.

The method has been applied to LPE GaAs layer on $\mathrm{n}^{+}$substrate. The epitaxial layer was undoped and with an electron concentration of $1.4 \times 10^{14} \mathrm{~cm}^{-3}$. In such a material, a hole trap at $0.64 \mathrm{eV}$ from the valence band has been found [6] which is also found in VPE and bulk GaAs from measurements in $\mathrm{p}^{+}-\mathrm{n}$ junctions. Semitransparent gold barriers, with a thickness between 200 and $300 \AA$, were evaporated on the epitaxial layer.

No transients are observed by applying a negative voltage to the Schottky barrier, but from illumination and switching off the light a transient due to hole trap was observed.

Illumination accross the semitransparent Schottky barrier was provided with a tungsten lamp and the capacitance transient was measured in the differential mode with a BOONTON 72 BD capacitance meter.

As light intensity is increased, the capacitance transient is increased, but for strong illumination at the initial instants departs from an exponential decay having the same time constant for a longer time. This fact can be interpreted, as indicated above, by saying that for a certain light intensity, the saturation is reached and all traps were emptied. Further increases in light intensities will cause electron and hole accumulation. We define the saturation capacitance, $C_{0 \varnothing}$, as the capacitance wich corresponds to the situation in which all traps are empty and can be calculated from extrapolation to time zero the exponential decay, as can be seen in figure 2. In figure 2, various capacitance transients can be seen for increasing light intensities. These measurements were taken at the same temperature and for zero bias.

The activation energy of the trap was obtained from transients at different temperatures from the emission equation.

$$
\tau_{\mathrm{p}}^{-1}=\sigma_{\mathrm{p}} v_{\mathrm{th}} N_{\mathrm{v}} \exp \left(-E_{\mathrm{t}} / k T\right)
$$

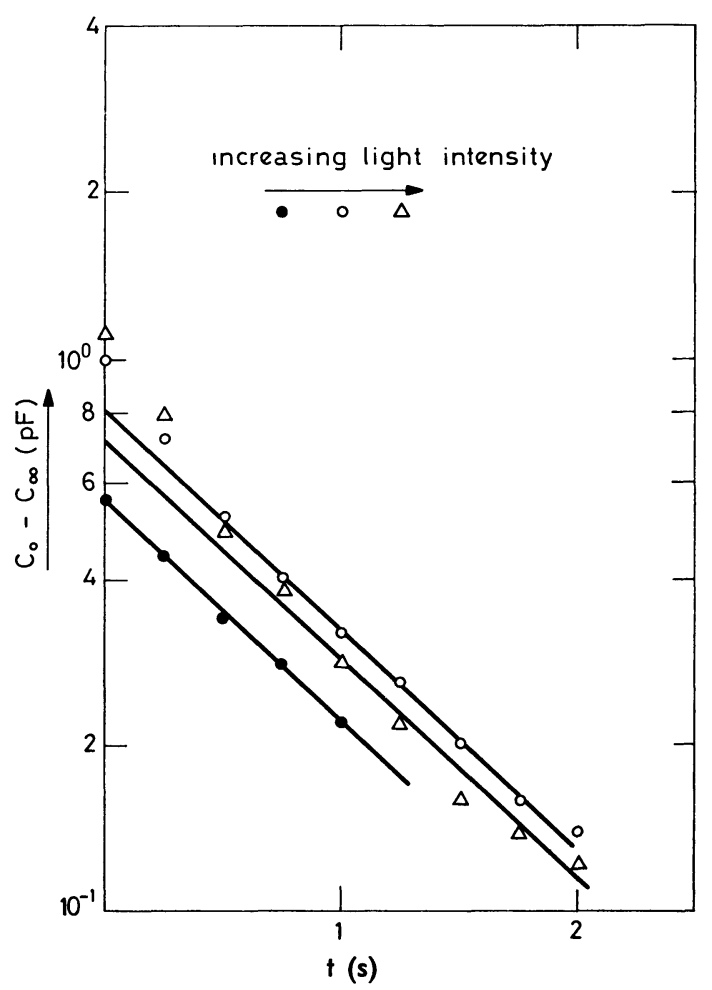

Fig. 2. - Capacitance transients at the same temperature and zero bias for different light intensities. 


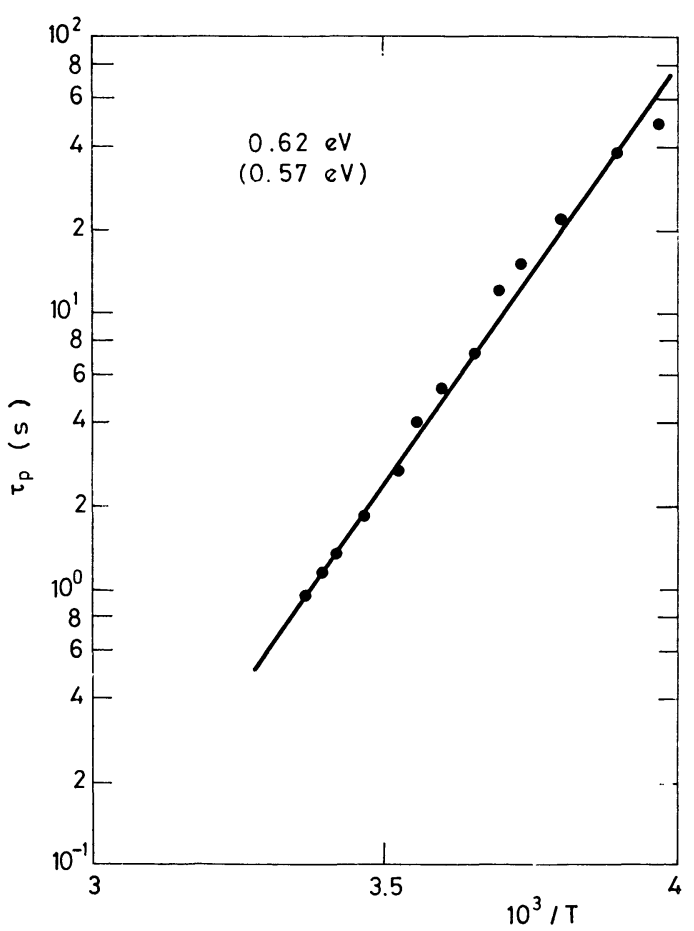

Fig. 3. - Time constants versus $10^{3} / T$. Hole trap level at $0.57 \mathrm{eV}$.

where $\sigma_{\mathrm{p}}, v_{\text {th }}$ and $N_{\mathrm{v}}$ are the capture cross-section, the thermal velocity and the effective density of states. An activation energy of $0.62 \mathrm{eV}$ which converts to $0.57 \mathrm{eV}$ if temperature dependences of $v_{\text {th }}$ and $N_{\mathrm{v}}\left(v_{\text {th }} \propto T^{1 / 2}\right.$ and $N_{\mathrm{v}} \propto T^{3 / 2}$ ) were taken into account in a reasonable agreement with previous results $[6,7]$.

In the assumption that in the saturation case all traps are empty, the deep center concentration can be calculated from

$$
N_{\mathrm{t}}=\frac{\left(C_{0 \varnothing}^{2}-C_{\infty, \mathrm{dark}}^{2}\right)}{e q S^{2}} 2 V_{\mathrm{bi}} .
$$

The estimated trap concentration from this equation results $0.96 \times 10^{13} \mathrm{~cm}^{-3}$.

From these experiments, we can conclude that both majority and minority trap levels can be detected in semitransparent Schottky barriers, but concentration of the deep centers only can be estimated if the saturation is obtained, or in other words, if capture crosssections differ considerably, in this case $\sigma_{\mathrm{n}} \gg \sigma_{\mathrm{p}}$.

In conclusion, the only restriction for obtaining the energy level is the same as in the case of capacitance transient with the applied voltage, that is, there is only one level or various levels with substantially differents time constants and capture cross-section $\sigma_{\mathrm{n}}$ and $\sigma_{\mathrm{p}}$ considerably different.

Relative to trap density the situation is more restrictive, and for an exact determination the following conditions must be fullfilled :

- All traps have to be fully ionized in the dark.

- Saturation is really obtained, that is, under strong illumination all traps become neutral.

Acknowledgments. - The author wish to thank to the Royal Society for the grant during the realization of present work, to Prof. P. N. Robson for his acceptance in the Electronic and Electrical Department of the University of Sheffield and to Dr. A. Majerfeld for his helpful suggestions.

\section{References}

[1] SAH, C. T., Solid. State Electron. 19 (1976) 975.

[2] Bleicher, M. and LaNGe, E., Solid-State Electron. 16 (1973) 375.

[3] LaNG, D. V., J. Appl. Phys. 45 (1974) 3014.

[4] LANG, D. V., J. Appl. Phys. 45 (1974) 3023.
[5] Ikoma, T. and Jeppson, B., Japan J. Appl. Phys. 12 (1973) 7.

[6] Hasegawa, F. and Majerfeld, A., Electron. Lett. 11 (1975) 286.

[7] Hasegawa, F. and Majerfeld, A., Electron. Lett. 12 (1976) 52. 